\title{
Fibrillation of Aspen by Alkaline Cold Pre-treatment and Vibration Milling
}

\author{
Kärt KÄRNER *, Matti ELOMAA, Urve KALLAVUS \\ Centre for Materials Research, Tallinn University of Technology, Ehitajate tee 5, 19086, Tallinn, Estonia \\ cross'ref $\mathrm{http} / / / \mathrm{dx}$.doi.org/10.5755/j01.ms.22.3.7412
}

Received 23 June 2014; accepted 17 May 2015

\begin{abstract}
In this article an attempt to fibrillate aspen bleached chemi-thermo mechanical pulp (BCTMP) fibre in an environmentally friendly way is reported. The effects of various $\mathrm{NaOH}, \mathrm{KOH}$, urea and ethanol aqueous solutions at lowered temperature were tested for pre-treatment. The pre-treatment was followed by vibration milling aiming to peel off outer cell wall layers and to fibrillate S2 layer of the aspen wood fibre. The effects of the treatments were evaluated by scanning electron microscopy (SEM). The results show that it is possible to fibrillate BCTMP aspen fibres by using alkaline aqueous solutions at low temperatures followed by a mechanical treatment. A strong dependence on fibrillation of cellulose on temperature, time and alkali concentration was established.
\end{abstract}

Keywords: SEM, cellulose, fibrillation, alkaline cold treatment, nanocellulose, MFC, vibration milling.

\section{INTRODUCTION}

Photosynthetic organisms such as plants, algae, and some bacteria produce more than 180 billion tonnes of organic matter each year due to the photosynthesis; cellulose makes up half of this biomass [1]. It consists of microfibrils that are bundles of elementary crystallites bridged by amorphous phases. Cellulose is the most important component of wood; it gives strength to wood. Cellulose is a homopolysaccharide composed of $\beta$-Dglucopyranose units that are linked together by $(1 \rightarrow 4)$ glycosidic bonds. Two D-glucopyranose units form a cellubiose unit that is the repeating unit in the cellulose chain. The polymer chains are bond together in twisted rope-like structures by intermolecular hydrogen bonding. The most abundant cellulose form is native cellulose also known as cellulose I which has two distinct crystalline forms, cellulose $I_{\alpha}$ and cellulose $I_{\beta}$. Cellulose I can be transferred irreversibly to stabile crystalline form of cellulose II by regeneration and mercerization process by using $\mathrm{NaOH}[1]$.

The smallest building element of the cellulose skeleton is an elementary fibril which is a bundle of 36 parallel cellulose molecules, which are held together by hydrogen bonds. During growth of the tree, the cellulose molecules are arranged together in the form of microfibrils, which are $10-20 \mathrm{~nm}$ wide. Microfibrils are combined to greater fibrils and lamella (bundle of microfibrils, sometimes called macrofibrils) and they finally build up cellulose fibres. Mostly cellulose makes up the cell walls of the fibres.

Pulping is a process to separate wood fibres; it can be roughly divided into two: chemical pulping and mechanical pulping. Because a complete purification of cellulose demands a lot of energy and chemicals, there are many products in which cellulose is used only partly purified. For example, products like bleached chemithermo mechanical pulp (BCTMP) have been developed to

\footnotetext{
* Corresponding author. Tel.: +372-51-18984; fax: +372-62-03153.

E-mail address: kartkarner@gmail.com (K. Kärner)
}

be used as a component in paper making. A characteristic property of mechanical pulp is that it retains most of the wood lignin present in the middle lamella and in the primary wall. This material that is present on the surface of BCTMP forms a physical barrier to inter fibre bonding due to the hydrophobic nature of lignin [2].

Therefore, it is essential to remove the lignin-rich material in order to fibrillate fibres and to produce e.g. nanocellulose. The hydrophobic lignin-rich material is also one of the main reasons for low inter-fibre bonding strength of mechanical pulp fibres [2]. On the contrary, when more cellulose fibrils are exposed, and more fibre separation takes place in the secondary wall, then interfibre bonding is likely to happen. At the same time, by removing specifically the lignin-rich material on the fibre surface it will not reduce much the yield [2].

Microfibrillated cellulose (MFC) or nanocellulose was invented by Turbak already in 1983 by using high pressure homogenizer [3]. MFC is a type of cellulose where wood pulp fibres have been rapidly expanded in surface area and opened into their sub-structural microfibrils by using chemical pre-treatment and mechanical treatment. Fully delaminated nanocellulose consists of long $(1-2 \mu \mathrm{m})$ microfibrils $(5-20 \mathrm{~nm}$ in diameter) and has the appearance of a highly viscous, shear-thinning transparent gel. MFC is a material produced from a fibrillation process, which may contain fibres, fibre fragments, fibrils and nanofibrils. Various chemical pre-treatments have been reported including TEMPO-mediated oxidation, enzymatic-assisted hydrolysis, acid hydrolyses, carboxymethylation and acetylation [1, 8,9-12]. Several mechanical devices are also used to cause cell wall delamination including high pressure homogenizer, microfluidizer, grinder, blender, PFI mill, mechanical stirrer, ultrasonication, cryocrushing, electrospinning $[3-7,11]$ However, when pulp fibre suspension is homogenized, it needs often several passes in order to increase fibrillation but that often leads to high energy consumption. Therefore, a combination of processes of chemical and mechanical treatments have been developed to facilitate mechanical treatment; by making fibres less stiff and cohesive it is possible to reduce 
the number of passes of mechanical treatment and therefore energy consumption [9, 12]. In MFC production values around $20,000-30,000 \mathrm{kWh} / \mathrm{t}$ are not uncommon (without pre-treatment) but while combining the mechanical treatment with certain pre-treatments, it is possible to decrease the energy consumption to 1000 $\mathrm{kWh} / \mathrm{t}$ [13]. All those abovementioned methods or combination of those can lead to different types of nanocellulose materials.

MFC is a spectacular material with broad spectrum of potential applications such as paper, coatings, barriers, food, cosmetics, pharmaceuticals, and electronics. Micro and nanofibrillated fibre bundles obtain high reaction ability. The price rises remarkably during the wood and pulp treatment processes, e.g. if wood costs $\$ 0.1-0.2 / \mathrm{kg}$, then pulp $\$ 0.6-0.8 / \mathrm{kg}$ and nanocellulose $\$ 20-100 / \mathrm{kg}$ [4].

The cellulose pulp obtained from refining is generally inhomogeneous on the nano scale still mostly consisting of crystalline cellulose microfibrils but with random amorphous domains within the structure. Furthermore, the size of fibres in mechanical pulp varies on the micron scale while the size of microfibrils ranges only from $10-40 \mathrm{~nm}$. The aim of fibrillating is to homogenize the size of cellulose microfibrils and the removal the primary $(\mathrm{P})$ and first secondary layer (S1) in order to expose the S2 layer [30].

During the fibrillation process the cellulosic pulp fibres undergo both internal and external fibrillation. External fibrillation refers to the peeling off of the external layers thus opening the S2 layer for further chemical, physical or mechanical treatment. The internal fibrillation loosens the fibre wall further enhancing the susceptibility of the fibre for further treatment or homogenization. However, MFC is usually obtained from different kraft pulps where lignin is already removed and S2 layer is visible which facilitates the further treatment of MFC preparation.

Cellulose is known to be insoluble in water and most of organic solvents. However, in some applications it is important to dissolve cellulose, e.g to produce regenerated cellulose but this task is normally complicated. Cellulose cannot be dissolved easily in common cheap solvents because of its inter-and intramolecular hydrogen bonding [18]. Cellulose can be dissolved with solvent that can release effectively the interchain hydrogen bonding in cellulose [18]. Traditional dissolution methods have some important limitations, mainly in costs and environmental issues. Therefore, it is essential to use alternative methods [17].

Alkaline pretreatment is well known for its efficiency in the delignification and is relatively more environmentally friendly than most of the other bleaching methods.

Complete lignin removal is impossible to obtain with solely alkaline pretreatment due to the recalcitrant structure of lignin attached to the holocellulose matrix.

In alkaline conditions both cellulose swelling and dissolution are possible. However, they are totally different processes as the cellulose swelling maintains the gross structure of cellulose at the same time changing its physical properties and sample volume. On the other hand, cellulose dissolution is a transition process from a twophase system to a one-phase system (clear solution) where the original supramolecular cellulose structure is destroyed [15]. Hence, same solvents can act as swelling or dissolution agents depending on conditions and cellulose properties [15].

It has been shown that cellulose can be dissolved completely in $7 \% \mathrm{NaOH} / 12 \%$ urea aqueous solutions at $10^{\circ} \mathrm{C}$ in 2 minutes [14] or in a two-step process by using first $14 \mathrm{wt} . \%$ aqueous and $24 \mathrm{wt} . \%$ urea solution at $0{ }^{\circ} \mathrm{C}$ followed by 7 wt. $\% \mathrm{NaOH}$ and 12 wt.\% urea solution [19]. However, according to Cui and Zhang [14] KOH / urea aqueous solutions do not dissolve in any concentration at low temperatures, it causes only swelling. At the same time, the optimum swelling conditions appear in 8-9 wt.\% $\mathrm{NaOH}$ and followed by freezing into solid mass by holding it at $-20{ }^{\circ} \mathrm{C}$ [16]. Moreover, by treating samples further in 5 wt. $\% \mathrm{NaOH}$ solution at room temperature can also cause complete dissolution of cellulose [16]. It is important to know, that there is a critical temperature $\left(T_{c}\right)$ for cellulose dissolution $-12.6^{\circ} \mathrm{C}$ (freezing point) which means that by lowering the temperature further, does not dissolve more cellulose [20].

Schwanninger et al. 2004 [22] studied the effect of vibratory ball milling in short time (up to $60 \mathrm{~min}$ ) and analysed results with FT-IR spectroscopy, it was found that this kind of mechanical treatment has a deep influence on wood and cellulose. The most obvious changes were caused by the decrease in the degree of crystallinity and degree of polymerization of cellulose; it was less affected by temperature increase and oxidation or radical reactions.

Microfibrillated cellulose (MFC) material is commonly inhomogeneous; it might contain nanofibrils, fibrillar fines, fibres and fibre fragments. Typical lengths of pulp fibres there are 1 to $3 \mathrm{~mm}$ and with widths $10-50 \mu \mathrm{m}$, diameter of microfibrils is approximately $28 \mathrm{~nm}$ [23].

In this study neither a complete dissolution of cellulose nor degradation of the cellulose molecules was aimed. Despite of chosen solvents capable to dissolve cellulose, the conditions were selected so, that part of the cellulose remained in the form of native fibres. Therefore, the reaction parameters were changed compared to the complete dissolution values - the alkali concentrations were chosen less concentrated, temperature not that low and treatments were carried out in shorter period of time. The goal of the first step was simply to peel off outer cell wall layers of aspen BCTMP fibre and partially fibrillate exposed S2 layer. It was also important to save the natural crystalline form of cellulose (cellulose I). Further mechanical treatment is expected to fibrillate loosen cell wall layers and release nanofibrillar network. The ultimate aim was to get microfibrillated cellulose (MFC) by using above described alternative to well-known treatments method.

\section{EXPERIMENTAL}

\subsection{Materials}

Aspen BCTMP was obtained from Estonian Cell Company. Commercially available technical grade acetone with $99.5 \%$ purity from APChemicals was used in the 
solvent exchange process. $\mathrm{NaOH}[40.0 \mathrm{~g} / \mathrm{mol}], \mathrm{KOH}$ [56.11 g/mol], analytical grade urea [99.0-101.0\%] and $\mathrm{HCl}[\mathrm{Mw}=36.46 \mathrm{~g} / \mathrm{mol}, \geq 37 \%]$ were supplied from Sigma Aldrich. Ethanol $[96.6 \%$ vol] and acetone [95.5\% vol] were of laboratory grade and used without further purification. Distilled water was readily used from the laboratory's own distilled water system.

For mechanical treatment a vibration mill Narva Erbisdard DDR- 6M9458 with glass balls with diameter of $10.2 \mathrm{~mm}$ were used.

\subsection{Methods}

For experimental part full factorial model of experiments, where 3 variables are changed at the same time to minimize the amount of needed experiments, was used in order to find optimal conditions for fibrillation.

For chemical pre-treatment, a mixture of aqueous solutions as solvent of cellulose was prepared by directly mixing alkali hydroxide, urea, ethanol and distilled water. Alkali concentration varied from 3-7 wt.\%; and urea concentration was $12 \mathrm{wt} . \%$ in all experiments. The amount of ethanol was kept also $20 \mathrm{~g}$ in each experiment, $\mathrm{KOH}$ and $\mathrm{NaOH}$ ratio was maintained $2: 1$. The reaction times were chosen $3 \mathrm{~min}$ and $7 \mathrm{~min}$, reaction temperatures $-3{ }^{\circ} \mathrm{C}$ and $-7{ }^{\circ} \mathrm{C}$. The mixture of desired alkali hydroxide, urea, and ethanol was pre-cooled to desired temperature and then $5 \mathrm{~g}$ of never-dried grinded BCTMP of aspen was added to the pre-cooled solution and stirred for desired time. After the cooling stage, sample was quickly neutralized with pre-heated $3 \% \mathrm{HCl}$ solution and then heated up to $70^{\circ} \mathrm{C}$, after that the sample was washed with distilled water.

In order to fibrillate aspen pulp fibres, vibration mill was used. For Vibration mill treatment, $2.4 \mathrm{~g}$ chemically pre-treated sample with $2 \mathrm{~g}$ of distilled water was put into vibration mill with 2 glass balls and milled for 30 minutes.

The most fibrillated sample after first step (cold treatment) was milled in ethanol and acetone in vibration mill by using the same conditions as mentioned above; milling without any liquid was also performed.

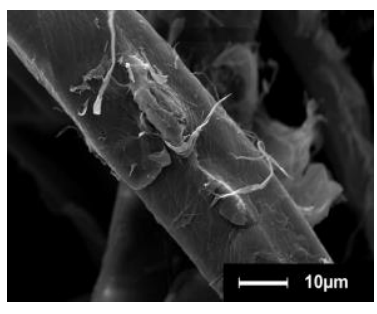

a-initial sample

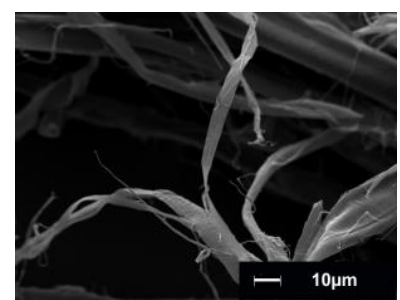

$\mathrm{b}$ - mild treatment $(\mathrm{A})$

Fig. 1. The influence of cold treatment

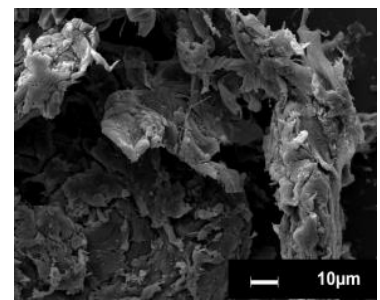

$\mathrm{a}$-without liquid environment

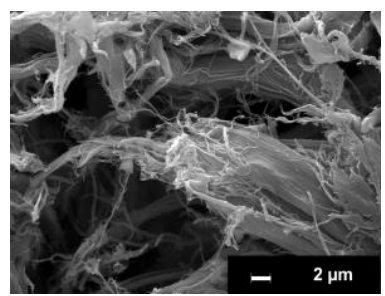

$\mathrm{b}$-in water

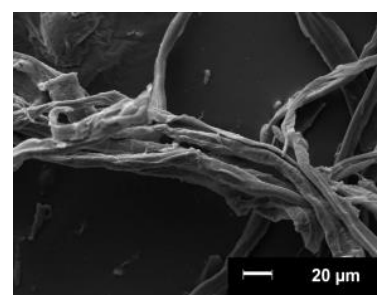

$\mathrm{c}$-heavy treatment $(\mathrm{F})$

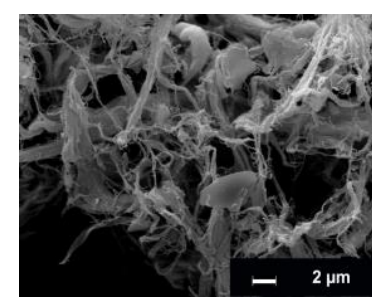

$\mathrm{c}-$ in acetone

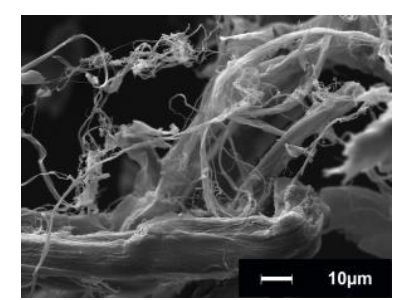

$\mathrm{d}$-short time strong alkali(H)

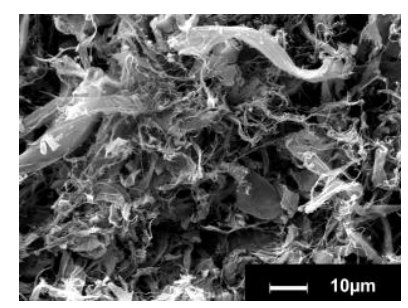

$\mathrm{d}-$ in ethanol

Fig. 2. The influence of mechanical treatment after the cold treatment 
Table 1. Parameters of $\mathrm{KOH} / \mathrm{NaOH}+$ urea solutions (edgepoints of factorial model)

\begin{tabular}{|c|c|c|c|}
\hline Exp. & $\begin{array}{c}\text { Concentration } \\
\text { of alkali,wt.\% }\end{array}$ & Time, min & $\begin{array}{c}\text { Temperature, } \\
{ }^{\circ} \mathrm{C}\end{array}$ \\
\hline A & 3 & 3 & -3 \\
\hline B & 3 & 7 & -3 \\
\hline C & 3 & 7 & -7 \\
\hline D & 3 & 3 & -7 \\
\hline E & 7 & 3 & -7 \\
\hline F & 7 & 7 & -7 \\
\hline G & 7 & 7 & -3 \\
\hline H & 7 & 3 & -3 \\
\hline
\end{tabular}

In initial sample, aspen BCTMP (Fig. 1. The influence of cold treatment), rectangularly shaped wood fibres were mostly unbroken, covered with $\mathrm{P}$ and $\mathrm{S} 1$ layer and remnants of middle lamella. As it can be seen from the Fig. 1. The influence of cold treatment, outer layers are strongly attached to the fibre main body. There is no sign of fine fibrillation. This is very typical morphology to mechanical pulp (including thermomechanical pulp, chemi-thermomechanical pulp, alkaline peroxide mechanical pulp and BCTMP) fibres, having outer cell wall layers and large pieces of non-fibrillar material on its surface $[25,26]$.

As outer layers of aspen BCTMP contain substantial amount of residual lignin and hemicelluloses that keep fibre together, then it is necessary to remove outer layers in order to further fibrillate fibres. It is essential that the cellulose-rich inner layer S2 will become visible after several further treatments and cellulose microfibrils will be separated from each other.

\subsection{Influence after cold treatment}

After mild treatment A (Fig. 1. The influence of cold treatmentb) numerous thin but wide cellulose lamellar structures were detached from the fibre surface. Treatment of fibres with $3 \mathrm{wt} . \%$ of alkali at $-3{ }^{\circ} \mathrm{C}$ and for $3 \mathrm{~min}$ (Fig. 1. The influence of cold treatment) effectively released lamellae but fine fibrillation was not present.

In conditions of heavy chemical treatment $F$ (Fig. 1. The influence of cold treatment c), when sample was treated in hardest conditions: $7 \mathrm{wt} . \%$ of alkali at $-7^{\circ} \mathrm{C}$ and for $7 \mathrm{~min}(\mathrm{~F}$, Table 1) there were no lamellas or fibrils visible. Fibres were distorted, wrinkled and the surface of fibres was partially dissolved. No fine fibrillation was present. It should consider as overtreatment but differently than it was referred in [25].

According to another edge of the factorial model sample was treated in short time (3 $\mathrm{min})$ but with strong alkali $(7 \%)$ according to data in Table $1 \mathrm{H}$ (Fig. 1. The influence of cold treatment d). Here, numerous bundles of microfibrils were separated from the fibre surface with the diameter of $10-50 \mathrm{~nm}$ and the sample showed good potential for the further treatment.

\subsection{Influence after mechanical treatment}

Performing vibration milling of aspen BCTMP fibres after chemical influence revealed the effect of weakening of strong intra- and intermolecular hydrogen bonding in cellulose and lead to the formation of microfibrillated cellulose bundles. Fibre morphology revealed in SEM directly after chemical treatment allowed only following most obvious changes in fibre surface morphology but did not give information about internal changes inside the fibre cell wall. The time of mechanical treatment with vibrator mill was highly dependent on following parameters: volume of sample container, size and amount of vibrator mill balls, amount of sample and solution that was used during milling. The treatment time $30 \mathrm{~min}$ - was chosen experimentally as well as the amount of the sample and solution used during the experiments according to the best results achieved so far in our laboratory.

Vibration milling without any liquid additive had no influence (Fig. 2. The influence of mechanical treatment after the cold treatment a) on the formation of any fine structures. Conversely, mechanical treatment "glued" fibres together and large mass of undefined lumps appeared.

Therefore, it is reasonable to carry out milling in liquid environment, preferably in polar solvent like water, ethanol, or acetone. For this experiment the most favourable sample $\mathrm{F}$ (Fig. 1. The influence of cold treatment d) was chosen as it showed the best potential for further delamination by mechanical treatment. Milling in water led to the effective release of microfibrils from the surface layer of the fibre (Fig. 2. The influence of mechanical treatment after the cold treatment $b$ ). The diameter of finest fibrils was measured less than $20 \mathrm{~nm}$. Also opening of the S2 layer with strongly orientated cellulose microfibrillar structure occurred. At the same time fines from the remnants of $\mathrm{P}$ and middle lamella stayed intact. Those fibre parameters are in good accordance with suggested MFC dimensions elsewhere [23, 24, 29, 30].

Vibration milling in the non-diluted acetone environment (Fig. 2. The influence of mechanical treatment after the cold treatment c) showed that fibrillation was not as fine as obtained with water. It is in good accordance to the results of [32]. The sample was well fibrillated but bundles of fibrils were couple of times wider compared of those obtained with the milling in water. Also some opening of S2 layer occurred. Non-orientated structures from compound middle lamella stayed intact.

An interesting effect occurred when samples were treated with vibration mill in the environment of ethanol (Fig. 2. The influence of mechanical treatment after the cold treatment d). Sample was almost all disintegrated into fibrillar bundles and fines. There were no large pieces of fibres visible. Fibrils obtained were as fine as with mechanical treatment in water. Fines from compound middle lamella were not affected by this treatment. According to the [32] the most significant changes in pine wood cell wall structures occurred with the treatment of wood with aqueous solution of ethanol, but current experiment showed the suitability of this solvent to the hardwood pulp fibres as well.

Cold treatment and vibration milling effects on cellulose have been investigated before by using instrumental methods of analysis (UV, FT-IR); those analyses have provided information about changes in cellulose crystallinity and constituents. [22] Morphology of mechanical pulp fibres have been studied by Li et al. (a) and (b) $[25,26]$ and outer cell wall removal by Kärner et 
al. [27] but the morphological changes after cold and mechanical treatment by using SEM evaluation have not been investigated yet by other authors.

Obtained material has great opportunity to be used in different potential applications such as aerogels [28], food and emulsion/dispersion applications, medical, cosmetic, pharmaceutical, and hygiene/absorbent products, nanopaper, nanocomposites [29, 30]. Due to the very fine fibrillar structure, obtained material has relatively high surface charge and therefore high reaction activity [31].

Therefore, it could be treated with suitable additive to obtain new functional material, e. g. antibacterial aerogel, by adding silver nanoparticles.

The results are unique because other authors have used different mechanical methods for pulp treatment. The use of full factorial model is also rather new in this field.

\section{CONCLUSIONS}

The effectiveness of chemical pre-treatment followed by vibration milling was evaluated by the changes in fibre's morphology and fibrillation using scanning electron microscopy. Even changes after certain treatments are caused by chemical interaction on molecular structure of aspen BCTMP fibres' chemical constituents, it is possible to visualise the result of these changes by looking closely at the fibres' morphology, delamination, opening of internal layers, external and internal fibrillation.

After cold treatment fibres turned softer, middle lamella, P and S1 layers detached from the top of the fibre, but fibres basically remained their full volume.

If chemical pre-treatment is successful and S2 layer is opened (visible in SEM), there is a great potential that mechanical treatment will cause cellulosic fibres to delaminate and form microfibrillated cellulose network.

Vibrator milling caused large fibres to disappear. This resulted in appearance of microfibrils and microfibrillar bundles, bulk came more uniform and S2 layer of the cell wall was opened and fibrillated. The effectiveness of whole treatment can be readily decided after vibration milling solely by fibre morphology visualized by SEM.

Some cold treatments seemed to be rather effective (cold treatment $\mathrm{H}$ ). Applying mechanical treatment in suitable environment after that resulted in deep delamination of the fibre cell wall. Additionally, some potential of successful mechanical treatment can be predicted based on the chemical treatment step, e. $g$ if there are signs of overtreatment, no further mechanical treatment will help to release microfibrils.

Vibrational milling in water and ethanol lead to similar results in respect to the formation of microfibrils and microfibrillar bundles. However, milling in the ethanol environment favoured disappearance of big fibre pieces.

It was noticed during the experiments, that even though some effective treatments caused the appearance of nice micro-and nanofibres, there is always some fraction of primary wall and middle lamellae remainders that cannot be subjected to any chemical or mechanical treatment. As those parts contain more lignin than cellulose, and the cellulose macromolecular network there is not strongly orientated, the fibrillation of these structures by current technology is not successful.

In this study, it was shown that it is possible to get MFC from BCTMP of aspen by using two-step process: chemical pre-treatment in alkaline environment followed by mechanical treatment with vibration mill. Resulting material contained very fine microfibrillar bundles; it was relatively uniform and promising alternative to MFC made from kraft pulp.

\section{Acknowledgments}

The authors would like to acknowledge the financial support of SmaCell project AR12138. This research was supported by European Social Fund's Doctoral Studies and Internationalisation Programme DoRa, which is carried out by Foundation Archimedes.

\section{REFERENCES}

1. Pérez, S., Samain, D. Structure and Engineering of Celluloses Advances in Carbohydrate Chemistry and Biochemistry 64 2010: pp. 25-116. http://dx.doi.org/10.1016/S0065-2318(10)64003-6

2. Li, K., Lei, L., Camm, C. Surface Characterization and Surface Modification of Mechanical Pulp Fibres Pulp \& Paper Canada January/February 2010: pp. 28-33.

3. Turbak, A. F., Snyder, F. W., Sandberg, K. Microfibrillated Cellulose, a New Cellulose Product: Properties, Uses, and Commercial Potential Journal of Applied Polymer Science: Applied Polymer Symposium 37 1983: pp. 815-827.

4. Yano, H. A Paradigm in Nanocellulose Materials. From nanofibers to nanostructured fibres Advanced Optical Materials 2(3) 2014: pp. 231-234. http://dx.doi.org/10.1002/adom.201300444

5. Uetani, K., Yano, H. Nanofibrillation of Wood Pulp Using a High-Speed Blender Biomacromolecules 12 2011: pp. $348-353$.

6. Herrick, F. W., Casebier, R. L., Hamilton, J. K., Sandberg, K. R. Microfibrillated Cellulose: Morphology and accessibility Journal of Applied Polymer Science: Applied Polymer Symposium 37 1983: pp. 797-813.

7. Chen, W., Yu, H., Liu, Y., Chen, P., Zhang, M., Hai, Y. Individualization of Cellulose Nanofibers from Wood Using High-intensivity Ultrasonication Combined With Chemical Pretreatments Carbohydrate Polymers 83 2011: pp. $1804-1811$.

8. Tonoli, G. H. D., Teixera, E. M., Corrêa, A. C., Marconcini, J. M., Caixeta, L. A., Pereirada Silvia, M. A., Mattoso, L. H. C. Cellulose Micro/nanofibers from Eucalyptus kraft pulp: preparation and properties Carbohydrate Polymers 89 2012: pp. $80-83$. http://dx.doi.org/10.1016/j.carbpol.2012.02.052

9. Alia, S., Besbes, I., Vilar, M. R., Mutjé, P., Boufi, S. Nonwoody Plants as Raw Materials for Production of Microfibrillated Cellulose (MFC): A Comparative Study Industrial Crops and Products 41 2013: pp. 250-259. http://dx.doi.org/10.1016/j.indcrop.2012.04.028

10. Zhang, J., Song, H., Lin, L., Zhuang, J., Pang, C., Liu, S., Microfibrillated Cellulose from Bamboo Pulp and its Properties Biomass and Bioenergy 39 2012: pp. 78-83. http://dx.doi.org/10.1016/j.biombioe.2010.06.013 
11. Lavoine, N., Deslodges, I., Dufrense, A., Bras, J. Microfibrillated Cellulose-Its Barrier Properties and Applications in Cellulosic Materials: A Review Carbohydrate Polymers 90 2012: pp. 735-764. http://dx.doi.org/10.1016/j.carbpol.2012.05.026

12. Henriksson, M., Henriksson, G., Berglund, L. A., Lindström, T. An Environmentally Friendly Method for Enzyme-assisted Preparation of Microfibrillated Cellulose (MFC) nanofibers European Polymer Journal 43 2007: pp. 3434-3441. http://dx.doi.org/10.1016/j.eurpolymj.2007.05.038

13. Siró, I., Plackett, D. Microfibrillated Cellulose and New Nanocomposite Materials: A Review Cellulose 17 2010: pp. 459-494.

14. Cai, J., Zhang, L. Rapid Dissolution of Cellulose in $\mathrm{LiOH} /$ Urea nad NaOH/Urea Aqueous Solutions Biomolecular Macromolecules 5 2005: pp. 539-548.

15. Zhang, Y.-H. P., Cui, J., Lynd, L. R., Kuang, L. R. A Transition from Cellulose Swelling To Cellulose Dissolution by o-Phosphoric Acid: Evidence from Enzymatic Hydrolysis and Supramolecular Structure Biomacromolecules 7 2006: pp. $644-648$.

16. Isogai, A., Atalla, R.H. Dissolution of Cellulose in Aqueous NaOh Solutions Cellulose 5 1998: pp. 309-319.

17. Medronho, B., Romano, A., Miguel, M. G., Stigsson, L., Lindman, B. Rationalizing cellulose (in)solubility: reviewing basic physicochemical aspects and role of hydrophobic interactions Cellulose 19 2012: pp. $581-587$. http://dx.doi.org/10.1007/s10570-011-9644-6

18. Zhang, N. L., Ruan, D., Gao, S. J. Dissolution and Regeneration of Cellulose in $\mathrm{NaOh} /$ thiurea Aqueous Solution Journal of Polymer Science: Part B: Polymer Physics 40 2002: pp. 1521-1529. http://dx.doi.org/10.1002/polb.10215

19. Qi, H., Yang, Q., Zhang, L., Liebert, T., Heinze, T. The Dissolution of Cellulose in NaOH-based Aqueous System by Two-Step Process Cellulose 18 2011: pp. 237-245.

20. Qi, H., Chang, C., Zhang, L. Effects of Temperature and Molecular Weight on Dissolution of Cellulose in $\mathrm{NaOH} /$ urea Aqueos Solutions Cellulose 15 2008: pp. 779-787

21. Kontturi, E. Cellulose:dissolution Advanced Biomaterial Chemistry and Technology Puu, Aalto University, 2012.
22. Schwanninger, M., $\quad$ Rodriques, J. C., $\quad$ Pereira, H., Hinterstoisser, B. Effects of Short-Time Vibratory Ball Milling on the Shape of FT-IR Spectra of Wood and Cellulose Vibrational Spectroscopy 36 2004: pp. 23-40.

23. Chinga-Carrasco, G. Cellulose Fibres, Nanofibrils and Microfibrils: The Morphological Sequence of MFC Components from a Plant Physiology and Fibre echnology Point of View Nanoscale Research Letters 6 2011: pp. $417-453$.

24. Chinga-Carrasco, G., Yu, Y., Diserud, O. Quantitative Electron Microscopy of Cellulose Nanofibril Structures from Eucalyptus and Pinus Radiata Kraft Pulp Fibres Microscopy and Analysis 17 2011: pp. 563-571.

25. Li, K., Tan, X., Yan, D. The Middle Lamella Remainders on the Surface of Various Mechanical Pulp Fibres Surface and Interface Analysis 38 2006: pp. $1328-1355$.

26. Li, K., Lei, X., Lu, L., Camm, C. Surface Characterization and Surface Modification of Mechanical Pulp Fibres Fibre Surface, Pulp and Paper Canada Jan/Feb 2010: pp. $28-33$.

27. Kärner, K., Elomaa, M., Kallavus, U. Lignin and Outer Cell Wall Removal by Using Supercritical $\mathrm{CO}_{2}$ extraction 9th International DAAAM Baltic Conference "INDUSTRIAL ENGINEERING” 2014: pp. 372-377.

28. Aegerter, M., Leventis, N., Koebel, M. M. Aerogels Handbook 1st Ed. New York, Springer, 2011: p. 932. http://dx.doi.org/10.1007/978-1-4419-7589-8

29. Klemm, D., Kramer, F., Moritz, S., Lindström, T, Ankerfors, M., Gray, D., Dorris, A. Nanocelluloses: A New Family of Nature-Based Materials Angewandte Chemie, Green Nanomaterials 50 2011: pp. 5438-5466.

30. Siró, I., Plackett, D. Microfibrillated Cellulose and New Nanocomposite Materials: A Review Cellulose 17 2010: pp. 459-494.

31. Kärner, K., $\quad$ Talviste, R., $\quad$ Viipsi, K., $\quad$ Kallavus, U. Enhancing the Surface Charge of BCTMP of Aspen with supercritical $\mathrm{CO}_{2}$ treatment, Baltic Polymer Symposium 2013 2013: pp. 87.

32. Meier, P., Stöör, E., Kaps, T., Kallavus, U. Mechanical Properties of Pinewood (Pinus Silvestris) Swollen in Organic Liquids Proceedings of the Estonian Academy of Sciences 12 2006: pp. 125-133. 